\title{
Representation of emotion in English syntax and teaching Russian EFL students
}

\author{
Svetlana Evgenyevna Rakhmankulova ${ }^{1 *}$, Tatiana Nikolaevna Sineokova ${ }^{1}$, Nadezhda \\ Alexandrovna Kokhan ${ }^{2}$, and Robert Alexeyevich Kuzmin ${ }^{1}$ \\ ${ }^{1}$ Nizhny Novgorod Linguistics University, Higher School of Translation and Interpreting, English \\ Language Department, Nizhny Novgorod, Russia \\ ${ }^{2}$ Nizhny Novgorod Linguistics University, Educational Programs Department, Nizhny Novgorod, \\ Russia
}

\begin{abstract}
The article looks into English simple utterances about a person's emotional state. The authors dwell on the ways the English simple sentence patterns are employed in utterances about emotional states and reveal the types of sentence patterns and types of propositions (event schemas) structuring emotional states. The authors also discuss the factors that determine the way a particular emotional event is conceptualized and structured and describe the mechanisms underlying the representation of emotional states in syntax and the choice of a sentence pattern for an utterance about this event. Special attention is given to the mechanism of conceptual metaphor that manifests itself in sentence patterns. The paper lists types of propositional schemas mapped onto concepts of emotional experiences and singles out regular correspondences between the source domain and the target-domain in these metaphorical mappings. The authors also tackle the issue of applying knowledge of sentence representation of emotional states in teaching Russian EFL students to use English syntax correctly and authentically. Teaching syntax in the proposed approach is aimed at helping students to assimilate propositional schemas of the English sentence as models of structuring reality with their metaphoric extensions and then to develop skills of employing these schemas in speaking.

Keywords: emotional states, sentence pattern, proposition, conceptual metaphor, EFL teaching.
\end{abstract}

\section{Introduction}

In linguistics of emotions the content of language units is viewed in terms of the dichotomy description vs. expression [1], or emotion talk vs. emotional talk [2]. In this paper sentence patterns are not considered as signals of the speaker's emotional state, but as language units describing emotions.

The syntax aspect of describing emotions in a language doesn't attract much attention of researchers. Representation of emotions in the lexical and phraseological system of language is studied by many famous linguists as well as in a great number of $\mathrm{PhD}$ papers (for overviews

\footnotetext{
*Corresponding author: tsvet.sveta@yandex.ru
} 
see [3]). Yet there are quite few papers on the sentence patterns employed for statements about a person's emotion (see, for instance $[4,5]$ ) and they do not study event schemas represented by syntax units. We might though mention a paper that highlights benefits of syntax analysis when looking into conceptual metaphors for the emotion concepts ROMANTIC LOVE and ANGER [6]. On the other hand, a number of works describe the repertoire of syntax patterns used to communicate the subject's emotions [7-9], but having other goals, the authors do not study conceptualization of emotional states.

This research is aimed at investigating event schemas structuring emotions in English and at revealing the potential of looking into propositional concepts and their representation in a language for teaching this language.

\section{Methods}

Since different scholars single out a different number of simple sentence patterns in English and in cognitive linguistics, and the lists of event schemas are few and varied (for an example see: [10]), we specifically dwelled on this issue and used a number of linguistic methods.

Applying the continuous sampling method, we selected simple, nonelliptical statements about emotions with neutral word order, independent of the context, from texts available in the English language corpora (British National Corpus, Corpus of Contemporary American English). We singled out the propositions (event schemas) underlying statements built upon the same sentence pattern, assuming that elements of a proposition become detailed in individual utterances with different lexical and grammatical scopes (e.g. WHO / WHAT IS WHAT. - He is a student; It is midnight; etc.), yet the sentences designate the same event type. Simultaneously, the system of event schemas structuring the English simple sentence was revealed through analysing the valency of verbs denoting prototypical events, such as be, go, do, give, etc. Different methods of traditional linguistics - definitional, etymological, contextual, and transformational analysis - were also used in the course of this study.

Next, we employed comparative and contrastive analysis to study sentence representations of emotional states in English and Russian in the same social, cultural and pragmatic contexts and revealed similarities and differences in conceptualization of emotional states in English and Russian exposed by similarities and differences in the structure of utterances about them.

\section{Results and discussion}

As a result of the ontological metaphoric transfer [11], components of emotion (the subject (a person), the object of emotion and its features (the source of emotion), the emotion itself, its external manifestations, its consequences $[12,13])$ can be represented discretely as participants in the event, and expressed as elements in the sentence pattern. Yet the indispensable elements of the event are the person and the emotion they experience. A person can be viewed as the only salient item, emotion being its attribute.

The relationship between the salient participants is interpreted as a physical event (utterances about emotions are built upon sentence patterns designed for prototypical events of sensory-motor experience) or some other non-physical event. This means that representation of emotion is not only metaphorical, which has often been pointed out (see, for instance $[14,15])$, but the metaphor is regularly manifested at the level of sentence pattern (for syntax metaphors also see [16]). The event can be structured according to the following propositional schemas: 
1. SOMEONE IS (FEELS, LOOKS) (LIKE) WHAT: I am furious; Don't look so sad; And then you will feel happy. Emotion is conceptualized as an observable property of an object.

2. SOMEONE ACTS: I have not yet grieved; Never fear; The king raged. The emotional state is viewed as a person's behaviour. The schema may be employed when the speaker's attention is focused on the physical manifestations of emotion: He is trembling with fear; He is going to burst with rage.

3. SOMEONE IS IN SOMETHING. Experiencing an emotion is compared to being inside something. The container schema is mapped onto an emotional state the following way: object - person; container - emotional state: She was in great distress; She's out of the doldrums. If the primary focus is placed on the emotion itself, it is represented as an object located in space and is expressed by the sentence subject. The person (metonymically, part of a body) is viewed as a container (EMOTION IS IN SOMEONE): There is joy in my heart; There was sheer terror in her eyes.

4. SOMEONE GOES INTO SOMETHING. A person is compared to a moving object, emotion - to a container or a liquid within a container: The nation plunged into deep grief; He flew into a rage; You can't jump out of depression. If the subject of the message is the emotion itself, the latter is mapped onto the subject of the sentence. The person is denoted (also metonymically) by the locative complement: Anger disappeared from his face; ... anger still flowed through him.

5. SOMEONE DOES SOMETHING. A person is someone who feels or possesses a feeling, or acquires it, loses it, shows it, etc.: But he did not find peace; He showed disgust by shaking his head vigorously. If the subject of the message is the emotion, it is viewed as a force affecting a person a certain way: Anger overwhelmed him; If happiness forgets you a little bit...; A grim mood gripped him.

6. SOMEONE GIVES SOMEBODY SOMETHING: It gives me pain when ...; You give me joy; It gave me a shock to realize that. The source of emotion is most salient and is interpreted as the subject, a person is viewed as the recipient, and emotion - as the transferred object.

Interpretation of emotion is thus inherently metaphorical, and in some statements there are several "layers" of metaphor. For example, in If happiness forgets you a little bit an abstract entity (happiness) is represented as a discrete object and personified - viewed as possessing human features (forgets); absence of emotion is viewed as "being forgotten" by it.

It is important to point out that there are numerous restrictions on the use of all schemas but for the schema SOMEONE IS (LIKE) WHAT: any emotional state when the speaker's attention is focused on a person and their emotional state may be expressed in a sentence with a nominal predicate: I am happy (sad, depressed, glad, disgusted, melancholic, frightened, afraid, ashamed, angry, etc.).

Knowing how a particular type of event is structured and represented in the English sentence is obviously beneficial for EFL learners.

Firstly, beginners often feel uncertain about how to start an utterance in English or tend to start it in the ways of their native language. It might prove useful for Russian EFL learners to keep in mind that if one knows what or who they are talking about, they name this thing or person and always make it the first element of the sentence even if in their native language the structure of the sentence about this particular kind of event is different. Cf.: Меня это шокировало. - I was shocked (by this).

It is also essential to learn to use the right construction and word order. Referring to a schema made up from simple words (for instance, SOMEONE GIVES SOMEBODY AN EMOTION) instead of traditional descriptions in terms of verbal predicates, direct and 
indirect objects, SPO word order, etc., seems to be much simpler and immediately understandable by learners.

To advance the learners' mastery of English one might consider the similarities and differences in sentence representation of emotional states (like any other types of situations) in their native language and in English. Relying on similarities (and developing a skill of doing so through exercise) enhances positive language transfer, while being aware of differences helps diminish the negative language transfer effects.

Russian EFL learners have to be aware that, firstly, the number of Russian sentence patterns employed for utterances about emotion is bigger than that in English. That means that emotions are conceptualized differently in Russian and in English and some Russian schemas are not similar to any English one. For this reason, for instance, Russian impersonal sentences are rendered into English by personal ones: Мне радостно. - I ат hарру; Его трясет. - He is shaking. Several propositional schemas of the Russian sentence correspond to one schema in English, SOMEONE IS (LIKE) WHAT, which means that this schema has to be focused on in the classroom. For beginners it might be important to know that they are always safe using this schema when speaking about different types of emotional states.

Secondly, certain emotions might be conceptualized differently in English and in Russian and be described in sentences of different patterns. Thus, some emotions structured by the proposition КТО ДЕЙСТВУЕТ cannot be structured by the proposition SOMЕONE ACTS. Therefore, many Russian statements with verbal predicates do not have structural equivalents in English, though some do: cf. Она грустит. - She is (feels) sad; Они горюют. - They are grieving. So, a learner has to know that they needn't search in vain for a verb for the word padyemcr, but employ a different schema instead.

Moreover, there might be even subtler conceptual differences across the languages. Unlike in Russian, in English the schema SOMEONE IS IN A STATE is rather mapped onto a physical condition and is therefore restricted in use. For instance, though it's correct to say He was in shock, one can't say *He was in shock to hear that; since the construction implies emotional reaction to a stimulus. One has to say He was shocked to hear that. Naturally, it is also necessary to explain social, cultural and pragmatic factors of choosing language units, specific features of the vocabulary, including idiomatic expressions, that fill sentence patterns.

We believe that negative effects of native syntax transfer might be handled more easily by taking a cognitive linguistics approach to learning syntax. Differences in the structure of utterance have to be explained by conceptual differences across the languages. Learners have to understand that the same event may be conceptualized and structured differently in their native language and in the target language since different stages or elements of the same event may be brought into focus by two languages, different cultural metaphors might affect this. And if learners are immediately taught the propositional schemas for statements about a certain type of event, different from those in their native language, negative transfer may be diminished. Additionally, referring to conceptual differences might enhance students' interest for the foreign language and the foreign culture, and might develop a deeper cognitive empathy.

\section{Conclusion}

This paper has discussed how a certain type of event - someone's experiencing emotion - is metaphorically conceptualized and structured in English. We have described several types of regular mappings between propositional schemas of physical experience and emotional states. Utterances about emotional states are shown to be inherently metaphorical, and they may contain several layers and types of metaphor. The structural differences of statements about emotion reveal different construals of the same event by different speakers. 
This might be explained to Russian EFL learners in order to give them a better understanding of the target language and of how utterances are made. Special attention might be paid to similarities and differences in sentence representation of emotional states in Russian and in English as factors of positive and negative language transfer. Since differences arise from different interpretations of the same real-world event, it might be useful to understand these conceptual differences and to learn to employ the event schemas of the target language. This may help ESL learners to make structurally correct utterances.

\section{Acknowledgments}

The reported study was funded by RFBR, project number 20-013-00361.

\section{References}

1. V. Shakhovsky, Neophilology, 22, 217-225 (2020). https://doi.org/10.20310/25876953-2020-6-22-217-225

2. M. Bednarek, Emotion talk across corpora (Palgrave Macmillan, New York, 2008)

3. J. Mackenzie, L. Alba-Juez, Emotion processes in discourse, in Emotions in discourse, 3-28 (John Benjamins, Amsterdam, 2019). https://doi.org/10.1075/pbns.302.01alb

4. E. Obarevich, Kognitivnyy aspekt angliyskikh predlozheniy-vyskazyvaniy, peredayushchikh situatsii emotsional'nogo sostoyaniya [The Cognitive Aspect of English Sentences That Represent Emotional States]. Dissertation for the degree of Candidate of Philological Sciences (Tambov State University named after G.R. Derzhavin, Tambov, 2004). Accessed on: December 15, 2020. [Online]. Available: http://www.lib.ua-ru.net/diss/cont/93747.html

5. N. Talashova, Gender manifestations in descriptions of negative emotions in English fiction (Saint Petersburg State University, Saint Petersburg, 2016)

6. D. Glynn, Cognitive Approaches to Metaphor, 36(3), 541-559 (2002). https://www.jstor.org/stable/10.5325/style.36.3.541

7. M. Lampropoulou, Linguistic Approaches to Emotions in Context, 137-158 (2014). https://doi.org/10.1075/pbns.241.09lam

8. V. Ozyumenko, Russian Journal of Linguistics, 1, 126-143 (2015)

9. T.N. Sineokova, Syntax of English emotional speech: a training manual (RuScience, Moscow, 2020)

10. R. Dirven, M. Verspoor, Cognitive exploration of language and linguistics

(Amsterdam, Philadelphia, John Benjamins Publishing Company, 2004). Accessed on: January 04, 2020. [Online]. Available:

https://www.academia.edu/19696305/Cognitive_Exploration_of_ Language_and_Linguistics_CLIP_1_revised

11. G. Lakoff, M. Johnson, Metaphors we live by (University of Chicago Press, Chicago, 2003)

12. C.E. Izard, Perspectives on Psychological Science, 2, 260-280 (2007). https://doi.org/10.1111/j.1745-6916.2007.00044.x

13. K. Scherer, Social Science Information, 44(4), 695-729 (2005).

https://doi.org/10.1177/0539018405058216

14. Z. Kövecses, Acta Universitatis Sapientiae, Philologica, 2, 197-220 (2010) 
15. O.M. Pastae, Journal of Linguistic and Intercultural Education - JoLIE, 12(1), 139-150 (2019). https://doi.org/10.29302/jolie.2019.12.1.10.

16. S. Kuzmina, Moderna Språk, 107(2), 99-114 (2013) 